\title{
Photo-Physical Studies of PVC Mixed with Organotin (IV) Complexes
}

\author{
Duaa Ghazi ${ }^{1}$, Emad Yousif ${ }^{1 *}$, Dina S. Ahmed ${ }^{2}$, Hamsa Thamer ${ }^{1}$, Riyadh Noaman ${ }^{3}$, \\ Nasry Jassim Hussien ${ }^{4}$, Rahimi M. Yusop ${ }^{5}$ and Ali H. Jawad ${ }^{6}$ \\ ${ }^{1}$ Department of Chemistry, College of Science, Al-Nahrain University, Baghdad, Iraq. \\ ${ }^{2}$ Department of Medical Instrumentation Engineering, Al-Mansour University College, Baghdad- Iraq. \\ ${ }^{3}$ Chemical and Petrochemical Research Center, Corporation of Research and Industrial \\ Development, Ministry of Industry and Minerals, Baghdad, Iraq \\ ${ }^{4}$ Department of Chemistry, College of Education for Pure Science, Diyala University, Baqubah-Iraq. \\ ${ }^{5}$ School of Chemical Science and Food Technology, Faculty of Science and Technology, University \\ Kebangsaan Malaysia, 43600 Bangi, Selangor, Malaysia \\ ${ }^{6}$ School of Chemistry and Environment, Faculty of Applied Sciences, Universiti Teknologi MARA, \\ 40450 Shah Alam, Selangor, Malaysia \\ * Corresponding Author: emadayousif@ gmail.com.
}

\section{Abstract}

PVC undergoes through many damaging changes upon the exposure to UV light. The rate of photodecomposition constant have been calculated for PVC films as a method for evaluating the efficiency of the organotin(IV) complexes $\mathrm{Me}_{2} \mathrm{Sn}(\mathrm{L})_{2}, \mathrm{Bu}_{2} \mathrm{Sn}(\mathrm{L})_{2}$ and $\mathrm{Ph}_{3} \mathrm{Sn}(\mathrm{L})$ that are used as a photostabilizers after 300 hour of irradiation. The results have showed that the additives had reduced the rate of photodecomposition constant of PVC films significantly with comparison to PVC (blank). The $\left(K_{d}\right)$ value for PVC films was the highest $\left(1.04 \times 10^{-2} \mathrm{sec}^{-1}\right)$ in the absence of any additives, and the lowest value $\left(4.79 \times 10^{-3} \mathrm{sec}^{-1}\right)$ was in the presence of dimethyltin (IV) complex. The surface morphology of PVC films examined utilizing the atomic force microscope (AFM).

[DOI: 10.22401/ANJS.22.3.01]

Keyword: Photodegradation, Organotin(IV) complexes, Rate of photodecomposition constant, UV radiation, Atomic force microscope.

\section{Introduction}

In the vicinity of small municipal facilities, ground contamination and air pollution have become an environmental issue that should be addressed [3]. The incineration of plastics produces strong volatile carcinogenic dioxins, which is present in most dust particulates and municipal refuse, causing an environmental issue [1,2]. Process which deteriorates polymer properties due to chemical, physical or biological reactions that lead to chemical transformation are recognized as polymer degradation [4]. Degradation of polymeric materials occurs in different environments and service conditions, which leads to limit the lifetime of the polymer. Poly(vinyl chloride) has been, for more than 70 years, one of the most important and among the most frequently used plastics [5]. PVC under environmental factors - such as UV radiation from sunlight, and also moisture, temperature, and biological decay -suffers from chemical and physical changes in the structure of the material components of the polymer [6]. The changes evaluation in PVC properties under service conditions has become a significant issue, as this indicates the durability of PVC products [7]. Ultraviolet radiation are known have deleterious effects on the most polymers, inducing chemical modifications and chain scissions which ultimately lead to undesirable loss of mechanical and surface properties of irradiated material [8]. Susceptibility of PVC substances to incident light of $(300-400) \mathrm{nm}$ wavelength has been subjected of many investigations [9-12], since the monomer unit itself contains no chromophore that absorbs in the solar emission range. This work aim to investigate the effect of the synthesized organotin (IV) complexes [13,14], as photostabilizers for PVC by observing the photodecomposition rate constant as an evaluation method for the additives efficiency to reduce the damaging effects of UV radiation. 


\section{Materials and Methods}

Materials used

Ciprofloxacin and other chemicals supplied from Sigma-Aldrich Chemical Company (Gillingham, UK) and used as received.

\section{Experimental methodology}

Synthesis of organotin(IV) complexes

The di- and triorganotin(IV) complexes ciprofloxacin as ligand (1-cyclopropyl-6fluoro-4-oxo-7-piperazin-1-ylquinoline-3carboxylic acid) in methanolic medium with different ratios and formed off white colored powder. The complexes have been characterized by FTIR spectroscopy, UV-VIS spectroscopy, elemental analysis and conductivity measurements, as reported $[13,14]$. had been synthesized by the reaction with<smiles>NCCN1CCNCC1c1cc2c(cc1F)c(=O)c(C(=O)O[Sn](c1ccccc1)(c1ccccc1)c1ccccc1)cn2C1CC1</smiles>

$\mathrm{Ph}_{3} \mathrm{SnL} ; \mathrm{L}=$ ciprofloxacin

(a)<smiles>[R][Sn]([R])(C)OC(=O)c1cn(C2CC2)c2cc(N3CCNCC3)c(F)cc2c1=O</smiles>

$\mathrm{Me}_{2} \mathrm{SnL}_{2}, \mathrm{Bu}_{2} \mathrm{SnL}_{2} ; \mathrm{R}=\mathrm{Me}, \mathrm{Bu}$

(b)

Fig.(1): Triphenyltin(IV), (a) $\mathrm{Me}_{2} \mathrm{Sn}(L)_{2}$ and (b) $B u_{2} \mathrm{Sn}(L)_{2}$ complexes.

\section{PVC films preparation}

Fixed concentrations of poly(vinyl chloride) solution (5 g per $100 \mathrm{ml}$ ) in THF were utilized to synthesize polymeric films with $(40 \mu \mathrm{m}$ thickness) fixed by a Digital Vernier Caliper 2610A micrometer (Vogel $\mathrm{GmbH}$, Kevelaer, Germany). The prepared organotin(IV) complexes were added to the films of ( $0.5 \%$ by weight $)$ [15-17].

\section{Accelerated testing technique}

Accelerated weatherometer Q.U.V. tester (Philips, Germany), was used for irradiation of PVC films. These lamps are of the type (UV-B 313) giving wavelength range between (290 to $360 \mathrm{~nm}$ ) and the maximum wavelength light intensity is at $(313 \mathrm{~nm})$ with light intensity = $7.75 \times 10^{-7}$ Ein $\mathrm{Dm}^{-3} \mathrm{~S}^{-1}[18-20]$.

Photodegradation and evaluation of PVC stabilizing efficiency by ultra-violet spectroscopy

A Shimadzu UV-Vis 160A-Ultraviolet Spectrophotometer (Shimadzu Cooperation, Kyoto, Japan) was used to measure the changes in the UV-visible spectra of PVC films during irradiation $(\lambda \max =313 \mathrm{~nm})$ [21]. The photodecomposition rate constant $\left(k_{d}\right)$ of
PVC films were calculated [22], using Equation (1).

$$
\ln (a-x)=\ln a-k_{d} t
$$

Where, $a=A_{0}-A_{\infty}, x=A_{0}-A_{t}$

$a=$ stabilizer concentration before irradiation.

$x=$ change in stabilizer concentration after irradiation time $(t)$ as shown in Equation (2).

$$
a-x=A_{0}-A_{\infty}-A_{0}+A_{t}=A_{t}-A_{\infty} .
$$

$A_{0}=$ the absorption intensity of the PVC at $t_{0}$.

$A_{\infty}=$ the absorption intensity at $t_{\infty}$.

$A_{t}=$ the absorption intensity after irradiation time $t$.

Equation (3) was obtained by substituting $a-$ $x$ in Equation (1) by its value in Equation(2)

$$
\ln \left(A_{t}-A_{\infty}\right)=\ln \left(A_{0}-A_{\infty}\right)-k_{d} t
$$

\section{Results and Discussion}

Poly(vinyl chloride) has poor stability against light and may be due to abnormalities in the structure of the polymer such as carbonyl groups, hydroperoxide groups, and unsaturated terminal groups that are present in 
various types of commercially available polymer samples [8]. The bonds (C-C, C-H and $\mathrm{C}-\mathrm{Cl}$ ) of $\mathrm{PVC}$ are not expected to absorb light of wavelength longer than (190-220) $\mathrm{nm}$. The fact that free radicals are formed due to irradiation at long wavelengths (220-370) nm, give an indication of the existence of some types of chromophores in the polymeric chain $[23,29]$. During UV irradiation of polymers, carbonyl, hydroxyl and polyene groups are formed due to the photo-oxidation process. The change in UV-VIS spectrum of PVC during irradiation may indicate the formation of these groups. The formed carbonyl groups extend UV-VIS spectrum absorption to longer wavelengths between (200-400) nm. And it's generally accepted that carbonyl and polyene groups which are formed during UV irradiation, are responsible for the yellow color of the PVC [24].
The PVC films (40 $\mu \mathrm{m}$ thickness) containing organotin (IV) complexes $(0.5 \%$ by weight) were irradiated with a UV light $\left(\lambda_{\max }=313 \mathrm{~nm}\right)$ for 300 hours. PVC films during irradiation have undergone photolysis and clear changes took place. The effect of the prepared organotin(IV) complexes $\mathrm{Me}_{2} \mathrm{Sn}(\mathrm{L})_{2}$, $\mathrm{Bu}_{2} \mathrm{Sn}(\mathrm{L})_{2}$ and $\mathrm{Ph}_{3} \mathrm{Sn}(\mathrm{L})$ on the photostability of PVC films was investigated. By Plotting $\ln \left(A_{t}-A_{\infty}\right)$ versus time of irradiation $(t)$, a straight line which indicates the first order reaction and the slop equals the $\left(K_{d}\right)$ rate constant of decomposition. The change in $\ln \left(A_{t}-A_{\infty}\right)$ versus time of irradiation $(t)$ for PVC (blank) with the absence of any additives is represented in Fig.(2).

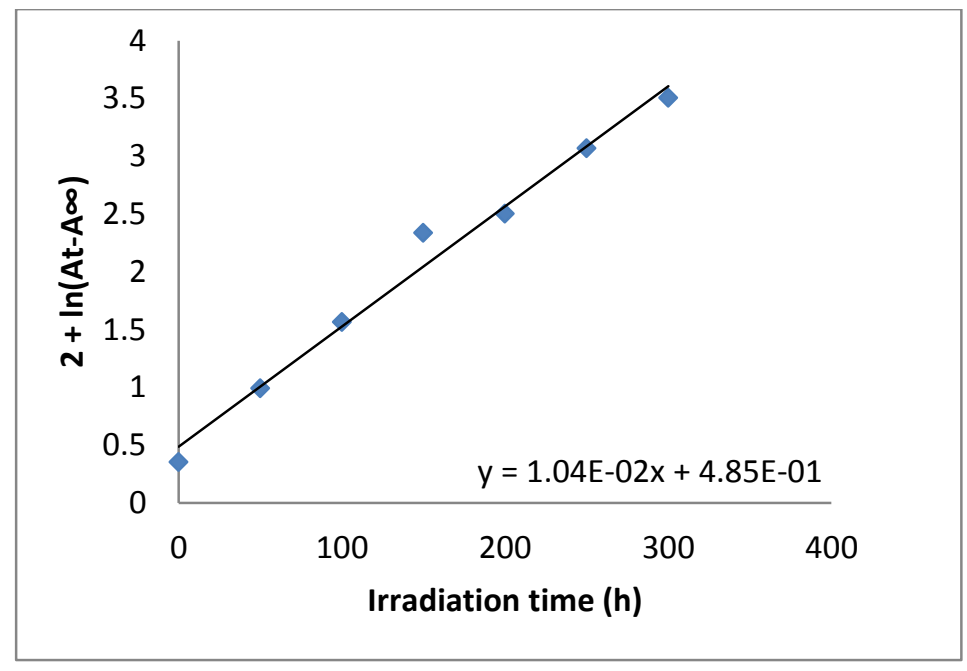

Fig.(2): Changes in $\ln \left(A_{t}-A_{\infty}\right)$ for PVC (blank) versus time of irradiation.

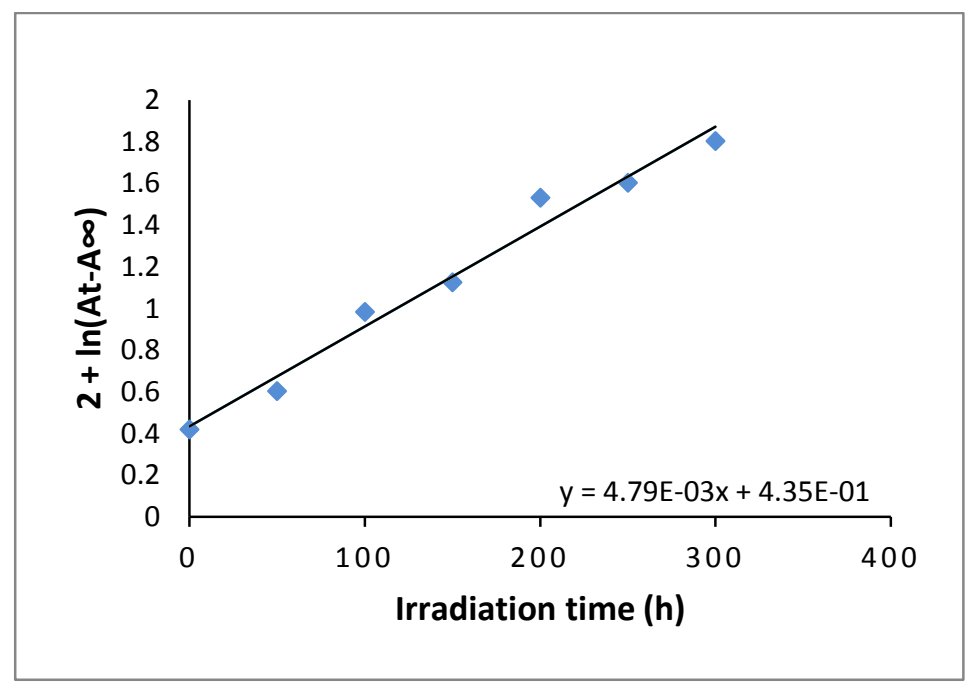

Fig.(3): Changes in $\ln \left(A_{t}-A_{\infty}\right)$ for PVC film containing $\mathrm{Me}_{2} S n(L)_{2}$ versus time of irradiation. 


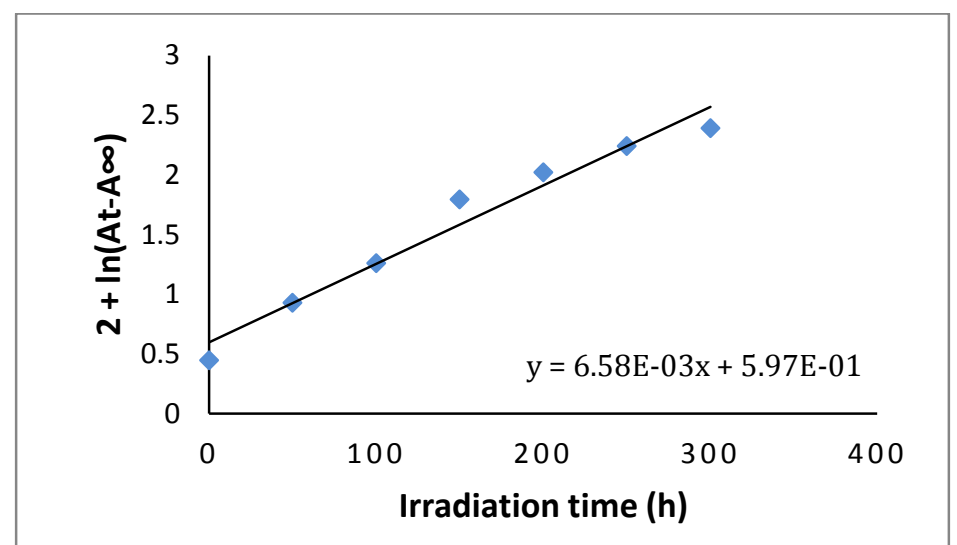

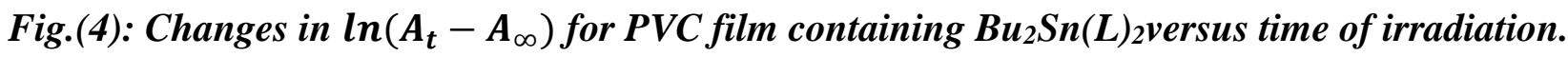

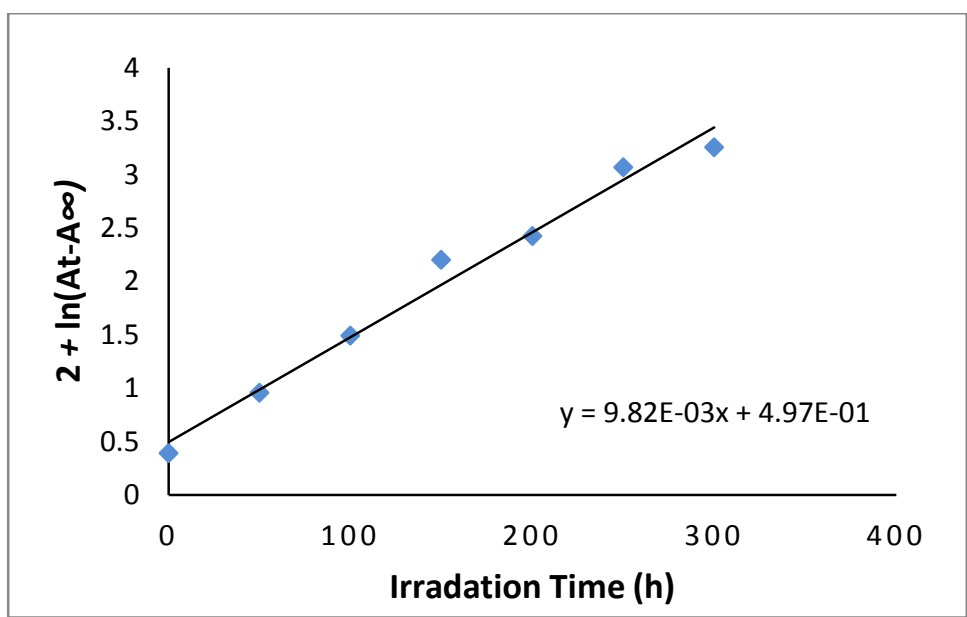

Fig.(5): Changes in $\ln \left(A_{t}-A_{\infty}\right)$ for $P V C$ film containing $P h_{3} S n(L)$ versus time of irradiation.

Fig.(3, 4 and 5) show the change in $\ln \left(A_{t}-A_{\infty}\right)$ versus time of irradiation for all additives in PVC films as stabilizers on irradiation with UV radiation. The photodecomposition rate constant $\left(k_{\mathrm{d}}\right)$ of all PVC films (40 $\mu \mathrm{m}$ thickness) with $(0.5 \%$ by weight) additives and without (blank) any additives was calculated by the same way and The $\left(k_{d}\right)$ values were computed using the UV spectra changes of PVC films $[19,25,30]$ as shown in Table (1).

\section{Table (1)}

The rate constant of photodecomposition (Kd) values for PVC films upon $U V$ irradiation for 300 hours.

\begin{tabular}{|l|c|}
\hline Compound & $\mathrm{K}_{\mathrm{d}}\left(\mathrm{S}^{-1}\right)$ \\
\hline \hline PVC $($ blank $)$ & $1.04 \times 10^{-2}$ \\
\hline \hline $\mathrm{PVC}+\mathrm{Me}_{2} \mathrm{Sn}(\mathrm{CIP})_{2}$ & $4.79 \times 10^{-3}$ \\
\hline \hline $\mathrm{PVC}+\mathrm{Bu}_{2} \mathrm{Sn}(\mathrm{CIP})_{2}$ & $6.58 \times 10^{-3}$ \\
\hline $\mathrm{PVC}+\mathrm{Ph}_{3} \mathrm{Sn}(\mathrm{CIP})$ & $9.82 \times 10^{-3}$ \\
\hline
\end{tabular}

From Table(1) notice that $\left(k_{d}\right)$ values are sensitive to the presence of organotin (IV) complex and its type. The $\left(k_{d}\right)$ value for PVC films was the highest $\left(1.04 \times 10^{-2} \mathrm{sec}^{-1}\right)$ in the absence of any additives and the lowest value $\left(4.79 \times 10^{-3} \mathrm{sec}^{-1}\right)$ was in the presence of dimethylTin(IV) complex. Rate constant of decomposition $\left(\mathrm{k}_{\mathrm{d}}\right)$ for PVC (blank) has been reduced significantly $\left(4.79 \times 10^{-3}\right.$ to $9.82 \times$ $10^{-3} \mathrm{sec}^{-1}$ ) when organotin(IV) complexes were used as additives. The efficiency of organotin complexes as photostabilizers during the photodegradation follows the order:

\section{$\mathrm{Me}_{2} \mathrm{Sn}(\mathrm{CIP})_{2}>\mathrm{Bu}_{2} \mathrm{Sn}(\mathrm{CIP})_{2}>\mathrm{Ph}_{3} \mathrm{Sn}(\mathrm{CIP})>$ $P V C$ (blank)}

Figures (6 and 7) are shown AFM 2D and 3D images for PVC (blank) and the one containing $\mathrm{Me}_{2} \mathrm{SnL}_{2}$ complex after 300 hours of irradiation, respectively. The roughness factor $(R q)$ can be evaluated PVC films surface smoothness [26]. High $R q$ value indicates dehydrochlorination and bond breaking which led to the rough surface [27,28]. Dehydrochlorination process normally 
occurs at high temperature [28]. $R \mathrm{q}=17.92$ for PVC (blank) was high compared to the addition of $\mathrm{Me}_{2} \mathrm{SnL}_{2}$ complex $R \mathrm{q}=1.08$ after 300 hours of irradiation.

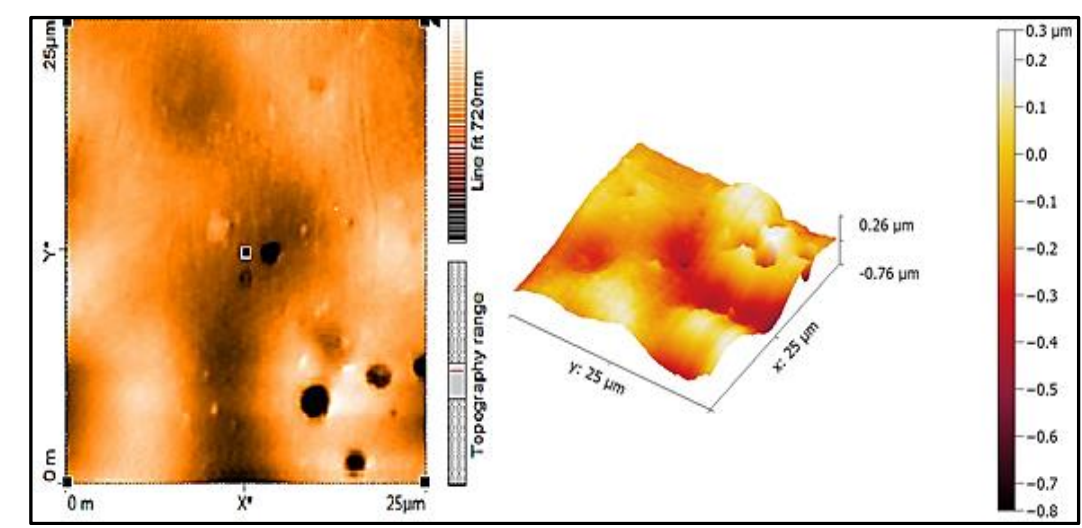

Fig.(6): AFM 2D and 3D images for PVC (blank) film after 300 hrs irradiation.

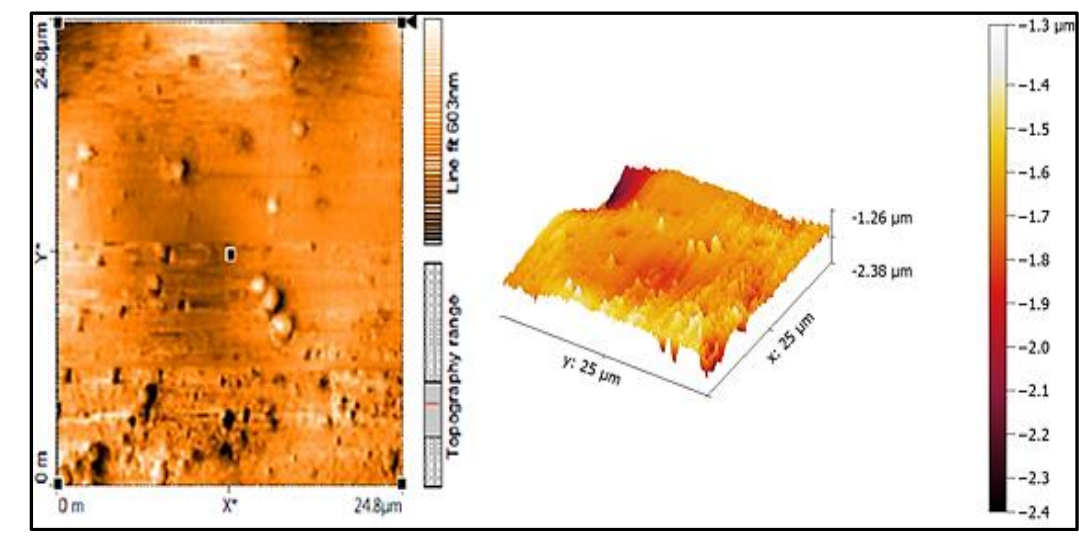

Fig.(7): AFM 2D and 3D images for PVC film containing Me $\mathrm{MenL}_{2}$ after 300 hrs irradiation.

Scanning electron microscopy (SEM) is a useful technique that can be used to test the compatibility of various components within polymeric materials. Such a technique can detect the various interfaces and separation phases within the polymeric matrix, which reflect both mechanical and thermal stability properties, and ionic conductivity [21]. Moreover, SEM images provide information about particle shape and size. It has been reported that the SEM images for the nonirradiated PVC (blank) showed smooth and neat surfaces with a high degree of homogeneity [14]. The SEM images, for the irradiated PVC (after $300 \mathrm{~h}$ of irradiation) are shown in Fig.(8). 


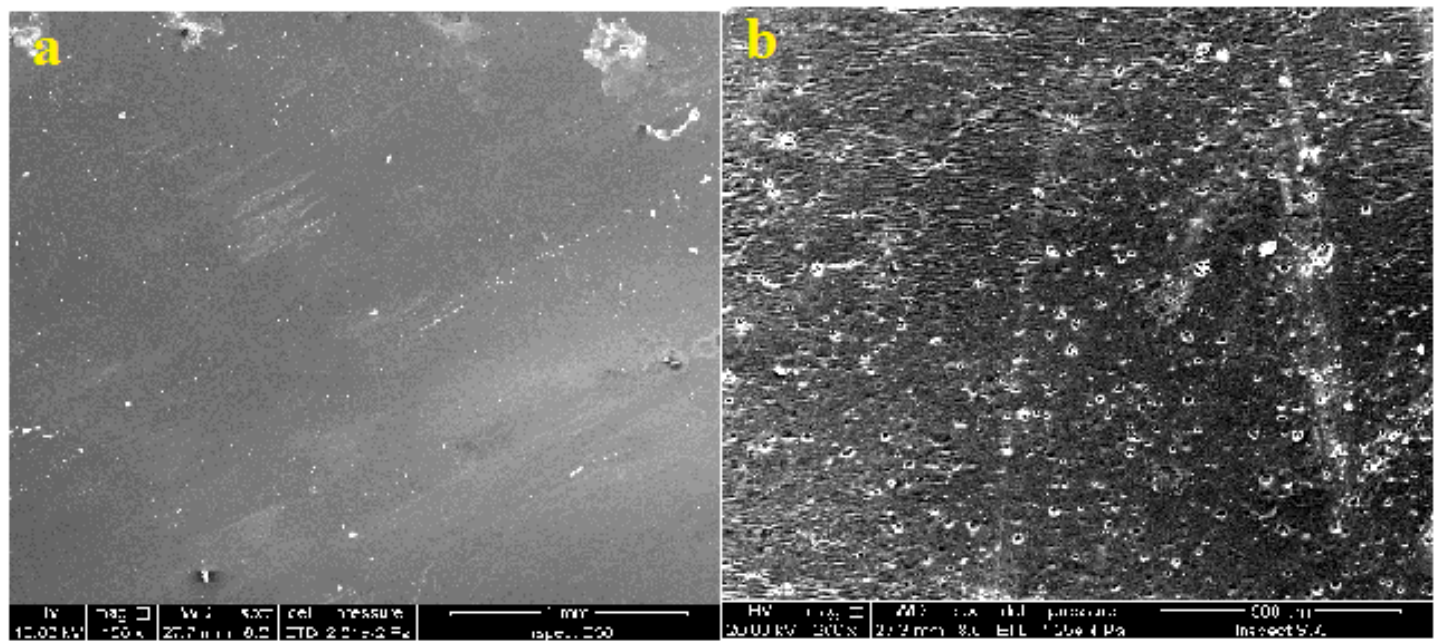

Fig.(8): SEM images of PVC (blank) films (a) before irradiation, (b) after irradiation.

\section{Conclusion}

The rate of photodecomposition constant of PVC films with and without organotin (IV) complexes after 300 hour of irradiation have been computed. The efficiency of the organotin (IV) complexes as photostabilizers was noticed through reducing the rate of photodecomposition constant compared to blank PVC that showed the highest value for $\left(\mathrm{K}_{\mathrm{d}}=1.04 \times 10^{-2} \mathrm{sec}^{-1}\right)$. PVC films containing organotin(IV) showed lower values for $\left(\mathrm{K}_{\mathrm{d}}=\right.$ $\left.4.79 \times 10^{-3}-9.82 \times 10^{-3} \mathrm{sec}^{-1}\right)$, while in the presence of dimethyltin (IV) complex $\left(\mathrm{k}_{\mathrm{d}}\right)$ value was the lowest indicating its higher efficiency to stabilize PVC during UV irradiation. The atomic force was utilized to assess the surface morphology of PVC films.

\section{Acknowledgments}

The project was supported by Al-Nahrain, Baghdad, Kebangsaan Malaysia, Nizwa Universities, Ministry of Industry and Minerals and Al-Mansour University College.

\section{References}

[1] Serrano D.P., Aguado J., Escola J.M., Garagorri, J. Conversion of low density polyethylene into petrochemical feedstock using a continuous screw kiln reactor. Anal. Appl. Pyrolysis, 58, 789-801, 2001.

[2] Takasuga T., Makino T., Tsubota K., Takeda N. Formation of dioxins (PCDDs/PCDFs) by dioxin-free fly ash as a catalyst and relation with several chlorinesources. Chemosphere, 40, 1003-1007, 2000 .
[3] Shah S.S., Ahmad I., Ishaq, M. Degradation study of used polystyrene with UV irradiation. Adv Mater Sci, 2, 1-6, 2017.

[4] Andrady A.L., Mark J.E (eds.) Physical Properties of Polymers Handbook. American Institute of Physics, Woodbury, New York, Chapter. 40, 547, 1996.

[5] Bothur J., Hohenadel R., Mieden O. Poly(vinyl chloride) (PVC). Carl Hanser verlag, Munich, Germany, 51-54, 2008.

[6] Yousif E., Aliwi M., Ameer A., Ukal, J. Improved Photostability of PVC Films in the Presence of 2-thioaceticacid-5-phenyl1,3,4-oxadiazole Complexes. Turk J Chem, 33, 339-410, 2009.

[7] Yousif E., Hasan A. Photostabilization of Poly (vinyl chloride)- Still on the Run: Review article. J Taibah Univ Sci, 9, 421448, 2015.

[8] Ye X., Pi H., Guo S. A Novel Route for Preparation of PVC Sheets with high UV Irradiation Resistance. J Appl Polym Sci, 117, 2899-2906, 2010.

[9] Gumargalieva K.Z., Ivanov V.B., Zaikov G.E., Moiseev Ju.V., Pokholok, T.V. Problems of ageing and stabilization of Poly(vinyl chloride). Polym Degrad Stab, 52, 73-79, 1996.

[10] Ahmed N.M., Mansour S.H., Abd-ElMessieh SL. Performance properties of pigmented polyvinyl chloride nanocomposites. Mater Design, 31, 43124320, 2010.

[11] Chaochanchaikul, K., Rosarpitak, V. and Sombatsompop, N. Photodegardation Profiles of PVC Compound and Wood/PVC 
Composites Under UV weathering. Exp. Polym Letters, 7, 146-160, 2013.

[12] Clough R.L., Gillen K.T. RadiationThermal Degradation of PE and PVC Mechanism of Synergism and Dose Rate Effects. Radiat Phys Chem, 18, 661-669, 1981.

[13] Ghazi D., Yousif, E. Design of organotin (IV) complexes derived from ciprofloxacin. Int. J. Res. Eng. Innov, 1, 63-65, 2017.

[14] Ghazi D., El-Hiti G.A., Yousif E., Ahmed D.S., Alotaibi M.H. The effect of ultraviolet irradiation on the physicochemical properties of poly(vinyl Chloride) films containing organotin(IV) complexes as photostabilizers. Molecules, 23, 254, 2018.

[15] Yousif E., Salimon, J., Salih, N. Mechanism of Photostabilization of Poly(methy methacrylate) Films by 2thioacetic acid benzothiazol Complexes. Arab J. Chem, 7. 206-311, 2014.

[16] Ali G.Q., El-Hiti G.A., Tomi I.H.R., Haddad R., Al-Qaisi A.J., Yousif E. Photostability and Performance of Polystyrene Films Containing 1,2,4Triazole-3-thiol Ring System Schiff Bases. Molecules, 21, 1699, 2016.

[17] Mohammed R., El-Hiti G.A., Ahmed A., Yousif, E. Poly(Vinyl Chloride) Doped by 2-(4- Isobutylphenyl)Propanoate Metal Complexes: Enhanced Resistance to UV Irradiation. Arab J Sci Eng, 42, 4307-4315, 2016.

[18] Yousif E., Hasan A., El-Hiti, G.A. Spectroscopic, Physical and Topography of Photochemical Process of PVC Films in the Presence of Schiff Base Metal Complexes. Polymers, 8, 204, 2016.

[19] Yousif E., El-Hiti G.A., Hussain Z., Altaie, A. Viscoelastic, Spectroscopic and Microscopic Study of the Photo Irradiation Effect on the Stability of PVC in the Presence of Sulfamethoxazole Schiff's Bases. Polymers, 7, 2190-2204, 2015.

[20] Ahmed D.S., El-Hiti G.A., Yousif E., Hameed A.S. Polyphosphates as Inhibitors for Poly(vinylChloride) Photodegradation. Molecules, 22, 1849, 2017.

[21] El-Hiti G.A., Alotaibi M.H., Ahmed A.A., Hamad B.A., Ahmed D.S., Ahmed A., Hashim H., Yousif E. The Morphology and Performance of Poly(Vinyl Chloride) Containing Melamine Schiff Bases against Ultraviolet Light. Molecules, 24, 803, 2019. [22] Yousif E., Asaad N., Ahmed D.S., Mohammed S.A., Jawad A.H. A Spectral, Optical, Microscopic Study, Synthesis and Characterization of PVC Films Containing Schiff Base Complexes. Baghdad Science Journal, 16, 2019.

[23] Rabek J.F. Polymer PhotodegradationMechanisms and Experimental Methods. Chapman \& Hall, London, 1995.

[24] Andrady A., Searle N. Photodegradation of Rigid PVC Formulations. II. Spectral Sensitivity to Light-Induced Yellowing by Polychromatic Light. J Appl Polym Sci, 37, 2789-2802, 1989.

[25] Alotaibi M.H., El-Hiti G.A., Yousif E., Ahmed D.S., Hashim H., Hameed A.S. Ahmed A. Evaluation of the use of polyphosphates as photostabilizers and in the formation of ball-like polystyrene materials. J. Polym. Res. 26, 161, 2019.

[26] Kara F., Akosy E., Yuksekdaged Z., Hasirci N., Aksoy, S. Synthesis and surface modification of polyurethanes with chitosan for antibacterial properties. Carbohydr. Polym, 112, 39-47, 2014.

[27] Zheng X.-G., Tang L.-H., Zhang N., Gao Q.-H., Zhang C.-F., Zhu, Z.-B. (2003). Dehydrochlorination of PVC materials at high temperature. Energy Fuels, 17, 896900, 2003.

[28] Pospíšil J., Klemchuk P.P. Oxidation Inhibition in Organic Materials; CRC Press: Boca Raton, FL, USA, 48-49, 1989.

[29] Yousif E., Ahmed D.S., Ahmed A.A., Hameed A.S., Muhamed S.H., Yusop R.M., Redwan A., Mohammed S.A. The effect of high UV radiation exposure environment on the novel PVC polymers. Environ. Sci. and Pollution Res, 26, 1-10, 2019.

[30] Ali M., El-Hiti G.A., Ibraheem H., Yousif E. Investigation of the Photodecomposition Rate Constant of Poly(Vinyl Chloride) Films Containing Organotin (IV) Complexes. J. Al-Nahrain Uni. Sci. 20, 18-23, 2017. 